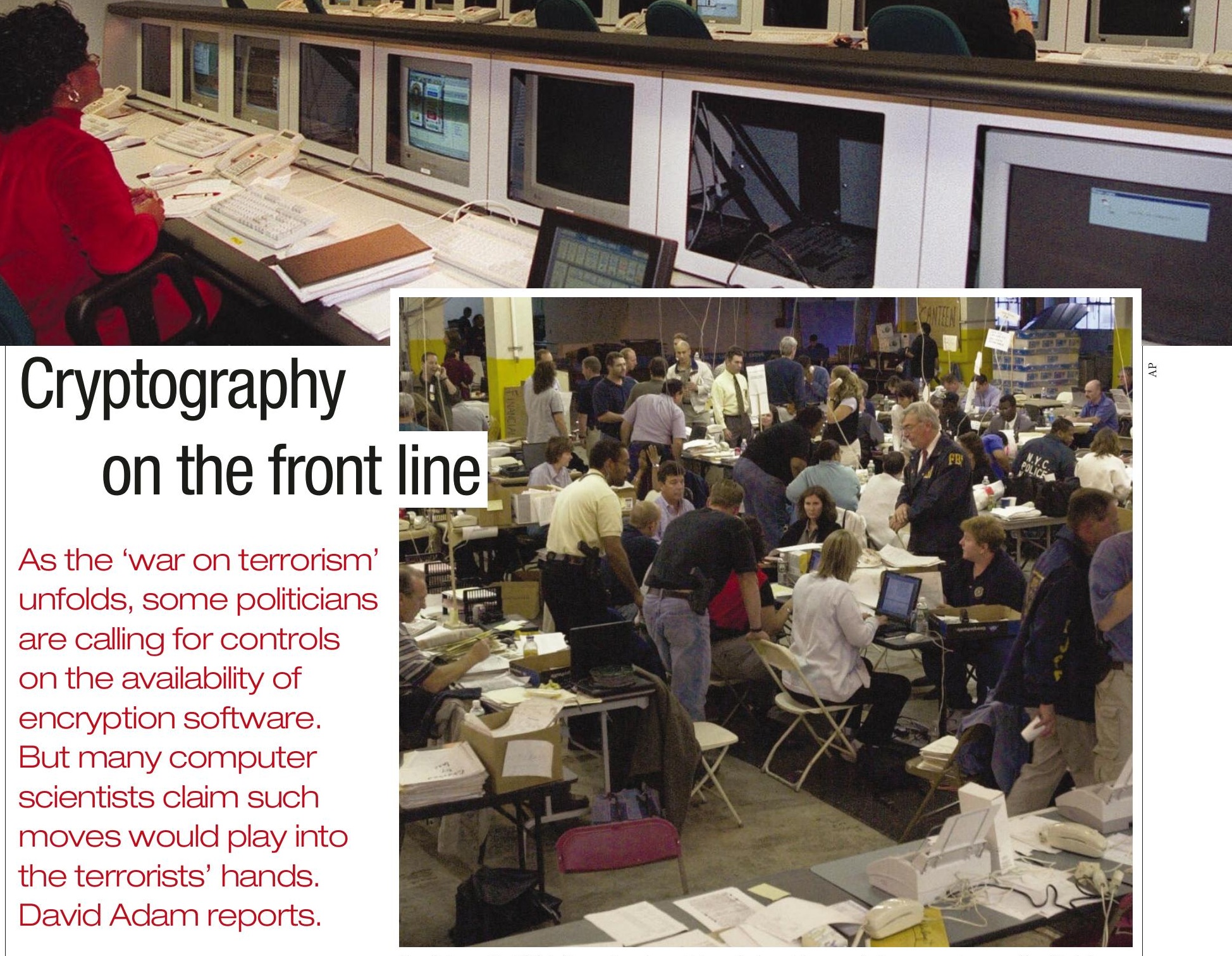

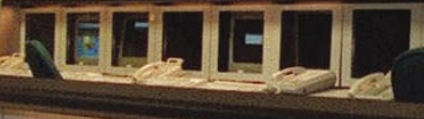
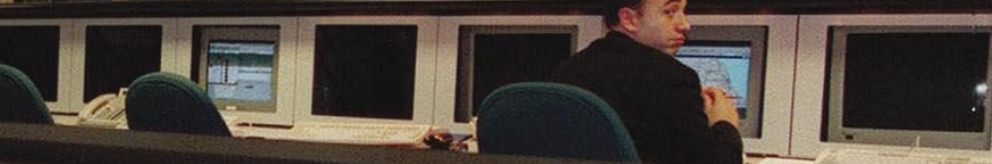
and their mathematical relationships with the keys are too complex for security agencies to crack, so access to the private key is in practice the only way to read an encoded message.

Intelligence and law-enforcement chiefs have long been concerned about the potential misuse of such programs. Indeed, former FBI director Louis Freeh in the late 1990s warned repeatedly that terrorists could be using encryption software to plan their actions, and he urged the US Congress to approve restrictions on its use and distribution.

\section{Added restrictions}

But Schneier claims it is impossible to limit the spread of cryptography. "Cryptography is mathematics and you can't ban mathematics," he says. There are almost 1,000 software products that use cryptography, available in more than 100 countries. "You would have to ban them in every country and even then it won't be enough, as any terrorist organization with a modicum of skill can write its own cryptography software," he says.

Blanket restrictions on the use of encryption might also impede the use of computers and the Internet in activities such as online

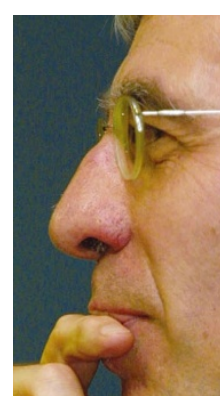

banking and shopping which rely on encryption for security. A degree of disruption to e-commerce may seem a small price to pay for greater security, but cryptography systems also protect vital safety systems, such as the computers used in air-traffic control. "Restrictions are Clampdown:

Louis Freeh (right) and Jack Straw not possible from a practiwant tighter curbs. research scientist with Florham Park, New Jersey.

If governments cannot crack encrypted e-mails and they are unable to stop people using them, what options do they have? One is to force manufacturers to introduce 'back doors' into their encryption software, allowing the content of encrypted messages to be monitored routinely. This can be achieved by a system known as key escrow, in which copies of all private keys are handed over to a third party and can be accessed on demand by government security agencies.

The arguments for and against key escrow raged through the 1990s. Agencies such as the FBI argued that it would allow secure monitoring of communications with little disruption to normal Internet use. Civil-liberties groups campaigned against key escrow on privacy grounds, whereas computer scientists concentrated on practical flaws. Researchers in the field say that it is currently impossible to build a system that is secure enough to hold all of the private keys and guarantee that they could not be accessed by those intent on committing fraud or wreaking cyber-havoc. Particularly daunting are the human factors - ensuring that individuals working for the key-holding organizations cannot be bribed or otherwise manipulated into releasing keys.

"It's all very well protecting bars of gold because at least you can see if they're gone in the morning," says Richard Clayton, who works in the computer security group at the University of Cambridge. "But when you're talking about lots of numbers hidden on behalf of people and you can't even tell if they've been stolen, then you're talking about needing a very secure system indeed. We're just not capable of building such systems." Schneier agrees: "Stockpiling keys in one place over an extended time period is a huge risk just waiting for attack or abuse."

Another problem with key escrow is that there is little commercial demand for encryption software that can be accessed at will by a third party - even in the name of national security. "It's not easy to demand that individuals use designated software," says Wenbo Mao, a researcher in the mathematics, cryptography and security group at

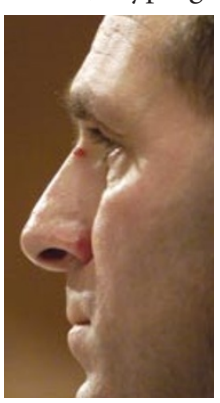
Hewlett Packard's UK laboratories in Bristol. "There is no market demand for it." Computer security experts are concerned that legislation enforcing key escrow would make legitimate computer users wary of using encryption technology - rendering their systems more vulnerable to attack.

With little incentive for software manufacturers to develop reliable key-escrow technology, the task falls to government agencies, which traditionally have kept this kind of research classified. But this approach is a problem, argues Mao — users have low confidence in a product that has not been subjected to widespread attempts to crack its codes. Indeed, the US government in the mid-1990s abandoned attempts to introduce its own key-escrow scheme, based on a system known as 'Clipper', after Blaze at AT\&T exposed flaws soon after it was released. "Government-certified systems developed behind closed doors would be a potential disaster," agrees Brian Gladman, a computer security consultant who formerly served as secure systems director with Britain's Ministry of Defence.

Computer scientists thought that they had won these arguments - but now the world has been thrown into conflict, they are not so sure. "If encryption is used in issues such as terrorism, and there is no legal way that law enforcement has access, then that has to be an issue," says a spokeswoman for the British government's National Criminal Intelligence Service.

Britain, in fact, last year passed a law that

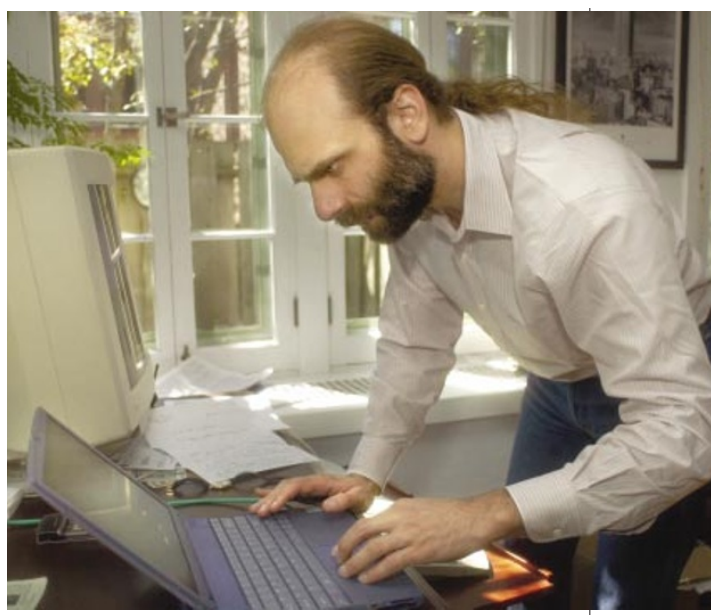

Summing up: Bruce Schneier urges governments to focus on improving computer security.

computer security experts point to as an example of the sort of legislation that might be proposed elsewhere in the current climate. The Regulation of Investigatory Powers Act, championed by Straw when he was home secretary, gives police wide-ranging powers to intercept e-mail traffic, and also allows them to force individuals to surrender their private decryption keys. Refusing to comply, or revealing that you have been asked to surrender your keys, can be punished with up to two years' imprisonment.

\section{Key questions}

These powers have not yet been invoked, so the impact of the law cannot be assessed. One problem is that the police must first show that seized private keys can be held securely. The scale of security needed for this more limited number of keys — which would not make such a tempting target — is not the same as that required for a full keyescrow system. But developing an appropriate system is still not easy. The British government admits that practicalities remain to be worked out, but says that it hopes to implement the law by the end of the year.

Given this, many computer scientists argue that the focus should not be on restricting the use of encryption, but on encouraging the development of stronger security systems to protect computer infrastructure vital for national and economic security.

To this end, President George W. Bush on 9 October appointed Richard Clarke, a former member of the National Security Council, to the post of special White House adviser for cyberspace security. "America built cyberspace and now it must defend cyberspace," Clarke said, in accepting the position.

Clarke's position on cryptography remains unclear. But even if he doesn't reopen the debate on encryption, other politicians and officials are determined to do so. Computer scientists who oppose such moves, it seems, will be forced to do battle once again. David Adam is a news and features writer for Nature. 